\title{
Relationship between personality and psychopathology in a longitudinal community study: a test of the predisposition model
}

\author{
M. P. Hengartner ${ }^{1 *}$, V. Ajdacic-Gross ${ }^{2}$, C. Wyss ${ }^{2}$, J. Angst ${ }^{2}$ and W. Rössler ${ }^{2,3}$ \\ ${ }^{1}$ Department of Applied Psychology, Zurich University of Applied Sciences, Zurich, Switzerland \\ ${ }^{2}$ Department of Psychiatry, Psychotherapy and Psychosomatics, University of Zurich, Zurich, Switzerland \\ ${ }^{3}$ Institute of Psychiatry, Laboratory of Neuroscience (LIM 27), University of São Paulo, São Paulo, Brazil
}

\begin{abstract}
Background. Mounting evidence supports the notion that personality is crucial in the aetiopathology of common mental disorders, but studies that allow for aetiological conclusions are lacking. The aim of the present study was thus to provide a test of the predisposition model.
\end{abstract}

\begin{abstract}
Method. We analysed data from the Zurich Cohort Study, a 30-year longitudinal epidemiological community study of an adult cohort $(n=591)$ from 1979 to 2008. Personality was assessed in 1988 with an established personality questionnaire, and psychopathology through seven semi-structured interviews between 1979 and 2008.

Results. On the basis of personality assessment from 1988, used as predictor of subsequent psychopathology (19932008), while adjusting for sex and prior mental disorders (1979-1988), neuroticism related significantly with future major depression episodes [odds ratio $(\mathrm{OR})=1.41$ ], anxiety disorders $(\mathrm{OR}=1.32)$ and depression treatment use $(\mathrm{OR}=$ 1.41). When participants with a past 10-year history (i.e. 1979-1988) of either major depression, anxiety disorder or depression treatment use were excluded, neuroticism in 1988 still significantly predicted first incidence (i.e. 1993-2008) of major depression episodes $(\mathrm{OR}=1.53)$ and depression treatment use $(\mathrm{OR}=1.84)$.

Conclusions. The present study provides compelling evidence that the personality trait of neuroticism constitutes an independent risk factor for subsequent major depression episodes and use of respective professional treatments, which serves as a proxy for particularly severe and impairing depression episodes. We therefore advocate that personality traits could provide clinically useful prognostic information when considered carefully.
\end{abstract}

Received 8 September 2015; Revised 14 January 2016; Accepted 15 January 2016; First published online 16 March 2016

Key words: Aetiopathology, epidemiology, neuroticism, personality, psychopathology.

\section{Introduction}

Various original studies have shown that personality traits are substantially related to mental disorders, psychosocial functioning impairments and behavioural problems, including depression and anxiety (De Graaf et al. 2002; Hettema et al. 2006; Kendler et al. 2006), personality disorders (Samuel \& Widiger, 2008; Hengartner et al. 2014b), substance abuse (Krueger, 1999; Turiano et al. 2012), sexual problems (Harris et al. 2008; Leeners et al. 2014), psychological and pharmacological treatment response (Quilty et al. 2008; Spek et al. 2008), schizophrenia spectrum disorders (Van Os \& Jones, 2001; Macare et al. 2012; Rössler et al. 2015) and mental health service use (Goodwin et al. 2002; ten Have et al. 2005). In

\footnotetext{
* Address for correspondence: M. P. Hengartner, Ph.D., Department of Applied Psychology, Zurich University of Applied Sciences (ZHAW), PO Box 707, CH-8037 Zurich, Switzerland.

(Email: michaelpascal.hengartner@zhaw.ch)
}

accordance, recent phenotypic and genetic findings suggest that personality is one of the main factors underlying general psychopathological impairment and both the severity and co-morbidity of mental disorders (Khan et al. 2005; Tackett et al. 2013; Caspi et al. 2014). It has thus legitimately been stated that maladaptive personality, that is, excessively high scores on normal personality traits as well as pathological personality traits and personality disorders, play a crucial role in the onset and development of psychopathology (Kotov et al. 2010; Krueger \& Eaton, 2010; Klein et al. 2011; Hengartner, 2015). The impact of personality is also highly significant for public health policies, preventive medicine and health economics (Lahey, 2009; Bogg \& Roberts, 2013). In their seminal study, Cuijpers et al. (2010) demonstrated that the excess costs uniquely related to the trait neuroticism are tremendous. For the year 2007 the authors estimated that in the Netherlands the excess costs attributable to the $25 \%$ highest scores of neuroticism were $\$ 1.39$ billion per 1 million inhabitants, which was approximately 
2.5 times higher than the costs attributable to mood, anxiety and substance use disorders (SUD) combined. However, the exact form of the relationship between personality and psychopathology is not unequivocally clear and there are various competing aetiological models (Klein et al. 2011; Widiger, 2011).

The predisposition model posits that personality constitutes an independent causal risk factor for the subsequent development of psychopathology, whereas according to the pathoplasty model personality affects only the course and severity of a mental disorder, but has no causal effect on the onset of the disorder. In addition, psychopathology may alter personality traits, as defined by the scar model (enduring effects) and the complication model (transient state effects). Finally, both the shared-factor model and the spectrum model posit that personality and psychopathology share the same underlying aetiological factor, with the former stating that both conditions have a common cause and the latter that both conditions are different manifestations along the same continuum (Clark, 2005). Presumably, the aetiological model with the greatest importance for psychiatric practice and public mental health is the predisposition model. If personality were to be confirmed as an independent risk factor causally related to psychopathology, then the clinical implication is that prevention and intervention should be targeted at personality traits, and not at their secondary psychopathological consequences (Soskin et al. 2012; Barlow et al. 2014).

However, a critical test of the predisposition model is methodologically demanding. First, in order to draw causal conclusions, longitudinal studies that cover a long observation period are necessary. Second, due to confounding, pathoplastic effects and common-cause factors, studies are needed that account not only for concurrent and subsequent psychopathology, but also for a thorough history of mental disorders prior to the assessment of personality. The aim of the present study was thus to provide a critical test of the predisposition model by using data from the Zurich Cohort Study, a longitudinal epidemiological study covering 30 years.

\section{Method}

\section{Participants and sampling procedure}

The Zurich Cohort Study originally comprised a cohort of 4547 subjects (males $=2201$; females $=2346$ ) representative of the canton of Zurich in Switzerland, who were screened in 1978 with the Symptom Checklist 90-R (SCL-90-R; Derogatis, 1977) when the men were 19 and the women 20 years old. Men and women were sampled with different approaches. In
Switzerland, every male citizen must undertake a military screening test at the age of 19 years. Therefore, conscripts within a defined catchment area comprise its respective, complete male age group. With the consent of military authorities, but independent of their screening procedure, we randomly screened $50 \%$ of all male conscripts of the canton of Zurich of this age group. The refusal rate was $0.3 \%$. Almost all men participated in the screening because they had to fill out various questionnaires for the armed services anyway. Since, with the exception of severely disabled persons, all Swiss men had to undergo military conscription at that time, drawing a random sample from conscripts allowed for the most representative male sample possible. As women were not obliged to serve in the army, female participants were identified from the complete electoral register of the canton of Zurich. Again, $50 \%$ of them were randomly selected and received questionnaires by mail, of which $75 \%$ responded. In order to increase the probability of the development of psychiatric syndromes, a stratified subsample of 591 persons $($ men $=292$; women $=299$ ) was selected for comprehensive interview, with two-thirds consisting of high scorers [defined by the 85th percentile or more of the Global Severity Index (GSI) of the SCL-90-R] and one-third being a random sample of subjects with scores below that 85th percentile. Such a two-phase procedure, i.e. initial screening and subsequent interview with a stratified subsample, is fairly common in epidemiological research (Dunn et al. 1999). A detailed description of the sampling method has been provided elsewhere (Angst et al. 1984).

Altogether seven interview waves have been conducted, specifically, in $1979(n=591), 1981(n=456)$, 1986 ( $n=457), 1988(n=424), 1993(n=407), 1999$ ( $n=$ $367)$ and $2008(n=335)$. The corresponding attrition rates were $0,22.8,22.7,28.3,31.1,37.9$ and 43.3. That is, even after 30 years of study duration, more than half of all participants continued to participate. Participant flow is indicated in Fig. 1. The initial allocation to the two groups, above and below the 85th percentile of the GSI, remained stable throughout the study; the dropouts were more frequent among the extremely high and extremely low GSI scorers (Eich et al. 2003). We repeated the attrition analyses after the most recent interview. There we found, in addition, no significant difference between subjects who had left the study and those who remained with regard to socioeconomic status and education as measured at the study outset, nor in their initial psychopathological impairment according to the nine SCL-90-R subscales. However, there was a moderate sex bias, with more dropouts among men [odds ratio $(\mathrm{OR})=1.82$, 95\% confidence interval 1.31-2.53, $p<0.001$ ]. 


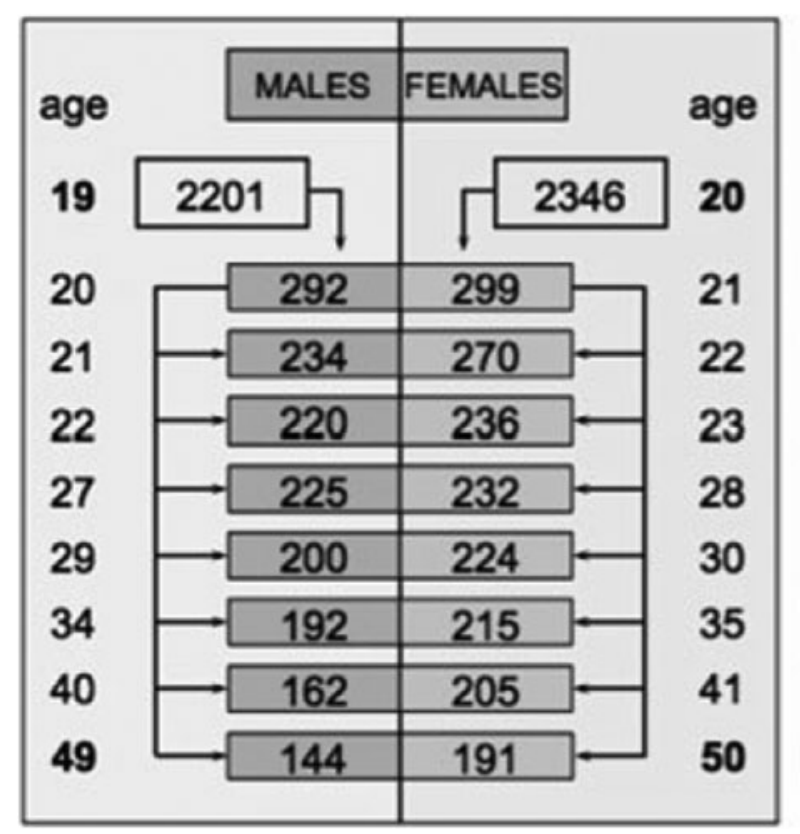

Fig. 1. Participant flow over the 30 years of study duration.

\section{Instruments and measures}

Interviews were conducted using the 'Structured Psychopathological Interview and Rating of the Social Consequences of Psychological Disturbances for Epidemiology' (SPIKE) (Angst et al. 1984). This semi-structured interview collects data on sociodemography, somatic syndromes, psychopathology, substance use, medication, health services, impairment and social activity. Its good reliability and validity have been reported previously (e.g. Angst et al. 2005). In contrast to other interviews [e.g. Composite International Diagnostic Interview (CIDI) and Structured Clinical Interview for DSM Disorders (SCID)], which focus on Diagnostic and Statistical Manual of Mental Disorders (DSM) diagnoses using a top-down approach with multiple cut-offs, the SPIKE interview uses a bottom-up approach assessing the past-year presence of about 14 somatic and 15 psychiatric syndromes, checking symptoms, duration, frequency and recency of episodes, distress, impairment and treatment. As described in detail elsewhere, diagnoses were based on DSM 3rd edition (DSM-III), 3rd edition revised (DSM-III-R) and 4th edition (DSM-IV) criteria (Angst et al. 2005). Major depressive episode (MDE) was diagnosed according to DSM-III-R and subsequently DSM-IV criteria. Dysthymia and minor depression were not included. For the present study we condensed generalized anxiety disorder (GAD), agoraphobia and social phobia into an umbrella diagnosis of anxiety disorder. We omitted obsessive-compulsive disorder and panic disorder from this
1978 Screening

1979 Interview

1980 Questionnaire

1981 Interview

1986 Interview

1988 Interview

1993 Interview

1999 Interview

2008 Interview

umbrella diagnosis because they did not show a sufficiently large incidence of new cases after personality assessment in 1988 (see Angst et al. 2016). Specific phobia was not included because the disorder is only moderately impairing or disabling when not secondary to other mental disorders (Depla et al. 2008). The proportion of participants with the umbrella diagnosis of anxiety disorder who specifically met criteria for social phobia across the follow-up period from 1993 to 2008 was $50.0 \%$ in $1993,26.8 \%$ in 1999 , and $40.9 \%$ in 2008 . The corresponding proportion of persons with an anxiety disorder who specifically met criteria for GAD across the same period was $51.4 \%$ in $1993,58.9 \%$ in 1999 , and $43.2 \%$ in 2008. Alcohol as well as drug abuse and dependence were subsumed under the broad umbrella diagnosis of SUD. Finally, professional treatment was defined as having consulted a medical doctor or psychologist in the 12 months prior to each interview and was analysed as a dichotomous variable (yes/no). Treatment was assessed separately for each syndrome and comprises psychological and psychopharmacological interventions. A diagnosis of MDE was not prerequisite for depression treatment use. Moreover, it is important to note that treatment is readily available in Switzerland. Every resident has a mandatory basic private health insurance and access to general and other practitioners, including psychotherapists. Use of professional treatment for depression was included in the analysis because it has been demonstrated to be a robust indicator of particularly severe and impairing depression episodes (Hengartner et al. 
2016). Since the common diagnosis of MDE according to DSM criteria shows little clinical utility as well as questionable reliability and validity (Parker, 2005; Lorenzo-Luaces, 2015), including an indicator of burdensome depression episodes irrespective of the diagnosis of major depression is clinically useful.

At the assessment in 1988, when participants were 29/30 years old, we examined the participants' personality traits using the Freiburg Personality Inventory (FPI; Fahrenberg et al. 1984). At that time the FPI was a widely used German personality inventory depicting personality traits on nine distinct scales. These traits are: (1) nervousness; (2) irritability; (3) depressiveness; (4) impulsivity; (5) sociability; (6) resilience; (7) aggressive dominance; (8) inhibition; and (9) frankness. The higher-order domains of the FPI originally proposed by the authors are neuroticism, extraversion and masculinity (Fahrenberg et al. 1984). However, some primary scales and in particular the domain of masculinity are conceptually outdated nowadays. Moreover, the original FPI scales do not bear close resemblance to the currently most frequently used big-five traits. Using a very large sample $(n>5000)$ and replication in six random subsamples thereof, extensive factor-analytic examination on item-level showed that the FPI items map onto the three domains of aggressiveness, extraversion and neuroticism (Angst \& Clayton, 1986). In the present study aggressiveness consists of 21 items and captures facets of proneness to violence, callousness and lack of self-control. The internal consistency of the aggressiveness domain was good (Cronbach's $\alpha=0.81$ ). Extraversion consists of 13 items and describes the broad domain of positive affectivity; that is, being outgoing, cheerful and selfconfident. The internal consistency of this domain was acceptable (Cronbach's $\alpha=0.72$ ). Finally, neuroticism consists of 16 items and captures the broad domain of negative affectivity, which comprises emotional liability, somatization and worry. Its internal consistency was also acceptable (Cronbach's $\alpha=$ 0.77). The correlations between these empirically derived domains and the original FPI scales are shown in Table 1. Further evidence for discriminant and convergent construct validity of these empirically derived personality domains was provided by examining their associations with the well-established coping resources of sense of mastery and self-esteem as assessed in the interview from 1986. Those coping dimensions were adapted from the highly cited work of Pearlin \& Schooler (1978). In accordance with a comprehensive meta-analysis conducted by Connor-Smith \& Flachsbart (2007), neuroticism and aggressiveness related negatively to both self-esteem and sense of mastery, while extraversion was positively associated. Taken together, the FPI has shown good reliability and validity (see also Fahrenberg et al. 1984, 2001). In addition, the higher-order domains of aggressiveness (also termed disinhibition or antagonism), extraversion and neuroticism are well replicated and very common in personality and psychopathology research (Clark, 2005; Markon et al. 2005; Hengartner et al. 2014a). Those domains also correspond closely to the three dimensions of neuroticism, extraversion and psychoticism as included in the Eysenck Personality Questionnaire (Eysenck \& Eysenck, 1975).

\section{Statistical analysis}

The longitudinal associations between personality and repeated measures of mental disorders were estimated using generalized estimating equations (GEE). These statistical models were introduced to fit regression analyses that account for within-subject correlation, which is an inherent part of longitudinal studies that rely on repeated measures (Zeger et al. 1988). GEE use all available data and impute missing values under the assumption of missing completely at random (MCAR). Prerequisite to the application of GEE is therefore a thorough missing value analysis, which revealed that all outcomes of interest met the criteria of MCAR according to Little's MCAR test. In a first series of prospective GEE models (see model 1 ) the repeated measures of mental disorder and depression treatment use from 1993, 1999 and 2008 were included consecutively as the dependent variables, while the three personality domains from 1988 were entered simultaneously as the independent predictor variables. We additionally adjusted for mental disorder prior to 1988; that is, the cumulative prevalence of a given disorder between 1979 and 1988, which was entered as a further independent variable. Adjustment for mental disorders between 1979 and 1988 allows for controlling for the effects attributable to the shared-factor and the spectrum models, since all variance in the outcome of interest that was accounted for by prior mental disorders rather than by the independent effects of personality domains per se was partialled out. Participants' sex was also included as a covariate since it relates significantly to both personality and mental disorders. Since the predisposition model requires a strict temporal sequencing where elevated personality scores have to be present before the first onset of severe mental health problems, we additionally ran a second series of prospective GEE models (see model 2) on a subset of participants with no history of MDE, anxiety disorder, SUD and depression treatment use from 1979 to 1988. In so doing, model 2 exclusively predicts the first incidence of depression, anxiety or SUD, respectively, between 1993 and 2008 after the personality assessment in 1988. By excluding participants with a 
Table 1. Pearson correlations of the empirically derived FPI personality domains with the original FPI scales and two dimensions of coping resources

\begin{tabular}{|c|c|c|c|}
\hline \multirow[b]{2}{*}{ Original FPI scales ${ }^{a}$} & \multicolumn{3}{|c|}{ Empirically derived scales ${ }^{c}$} \\
\hline & Aggressiveness & Extraversion & Neuroticism \\
\hline Nervousness & $0.41^{* *}$ & $-0.28^{* *}$ & $0.86^{* *}$ \\
\hline Irritability & $0.63^{* *}$ & -0.07 & $0.43^{* *}$ \\
\hline Depressiveness & $0.55^{* *}$ & $-0.44^{* *}$ & $0.79^{* *}$ \\
\hline Impulsivity & $0.82^{* *}$ & $-0.16^{* *}$ & $0.49^{* *}$ \\
\hline Sociability & -0.03 & $0.78^{* *}$ & $-0.21^{* *}$ \\
\hline Resilience & $-0.22^{* *}$ & $0.44^{* *}$ & $-0.33^{* *}$ \\
\hline Aggressive dominance & $0.73^{* *}$ & -0.08 & $0.36^{* *}$ \\
\hline Inhibition & $0.25^{* *}$ & $-0.82^{* *}$ & $0.50^{* *}$ \\
\hline Frankness & $0.44^{* *}$ & $-0.10^{*}$ & $0.27^{* *}$ \\
\hline Extraversion & $0.33^{* *}$ & $0.64^{* *}$ & 0.00 \\
\hline Neuroticism & $0.56^{* *}$ & $-0.43^{* *}$ & $0.77^{* *}$ \\
\hline Masculinity & $-0.19^{* *}$ & $0.57^{* *}$ & $-0.60^{* *}$ \\
\hline \multicolumn{4}{|l|}{ Coping resources ${ }^{\mathrm{b}}$} \\
\hline Sense of mastery & $-0.18^{* *}$ & $0.31^{* *}$ & $-0.37^{* *}$ \\
\hline Self-esteem & $-0.16^{* *}$ & $0.36^{* *}$ & $-0.35^{* *}$ \\
\hline
\end{tabular}

FPI, Freiburg Personality Inventory.

${ }^{a}$ Derived from Fahrenberg et al. (1984).

${ }^{\mathrm{b}}$ Derived from Pearlin \& Schooler (1978).

${ }^{\mathrm{c}}$ Derived from Angst \& Clayton (1986).

${ }^{*} p<0.05,{ }^{* *} p<0.01$.

diagnosis of affective disorders or SUD across the past 10 years prior to personality assessment, we also precluded that any association between personality and psychopathology was attributable to reversed causality such as the scar and the complication models. Owing to the dichotomous structure of the DSM-based diagnoses we computed all models with a binomial distribution and logit link-function. The within-subject covariance was specified with the "unstructured' correlation type to avoid having any constraints on the covariance structure, and a robust estimator was used to reduce the effects of outliers and influential observations. All analyses were performed with SPSS 23 for Windows (USA).

\section{Ethical standards}

All procedures contributing to this work comply with the ethical standards of the relevant national and institutional committees on human experimentation and with the Helsinki Declaration of 1975, as revised in 2008.

\section{Results}

Evidence for the convergent and discriminant construct validity of the personality domains of aggressiveness, extraversion and neuroticism is provided in
Table 1. The correlation of aggressiveness with extraversion and neuroticism was $r=-0.096$ and $r=0.480$, respectively, and the correlation between neuroticism and extraversion was $r=-0.367$.

In 1988 (i.e. at age 29/39 years), when personality traits were assessed, $15.9 \%$ of all participants lived alone, $85.6 \%$ lived in a committed relationship (in men $71.0 \%$ and in women $87.9 \%$ ), $51.7 \%$ were single, $42.2 \%$ were married, and $6.1 \%$ were separated/ divorced or widowed. A total of $36.1 \%$ had children (in men $24.0 \%$ and in women $46.9 \%$ ), $55.9 \%$ worked full-time (in men $84.5 \%$ and in women $30.4 \%$ ) and $26.7 \%$ worked part-time (in men $12.0 \%$ and in women 39.7\%). Further, in 1988 the unweighted 12 -month prevalence rates of the mental health problems included in the analysis were as follows: $11.3 \%$ for MDE, 9.9\% for depression treatment use, $11.6 \%$ for anxiety disorder, and $13.9 \%$ for SUD $(12.0 \%$ alcohol use disorder and $3.8 \%$ drug use disorder). Comprehensive epidemiological analyses of other mental disorders have been published previously (Angst et al. 2016) and are not repeated in detail here.

The results of model 1 are shown in Table 2. The cumulative prevalence rates of MDE, anxiety disorders and SUD between 1979 and 1988 were 31.5\% $(n=141)$, $20.2 \%(n=117)$ and $26.9 \%(n=119)$. The prospective associations of personality on repeated subsequent 
Table 2. Model 1: prospective associations between personality domains and psychopathology (407 participants)

\begin{tabular}{|c|c|c|c|}
\hline Outcome & Predictors & OR (95\% CI) & $p$ \\
\hline \multirow[t]{7}{*}{ MDE (1993-2008) } & MDE (1979-1988) & $2.03(1.31-3.14)$ & $0.002^{*}$ \\
\hline & Anxiety disorder (1979-1988) & $0.72(0.41-1.24)$ & 0.230 \\
\hline & SUD (1979-1988) & $1.44(0.85-2.44)$ & 0.180 \\
\hline & Female sex & $1.44(0.89-2.35)$ & 0.140 \\
\hline & Aggressiveness (1988) ${ }^{a}$ & $1.00(0.78-1.28)$ & 0.983 \\
\hline & Extraversion $(1988)^{\mathrm{a}}$ & $1.05(0.84-1.32)$ & 0.651 \\
\hline & Neuroticism $(1988)^{\mathrm{a}}$ & $1.41(1.09-1.82)$ & $0.010^{*}$ \\
\hline \multirow[t]{7}{*}{ Anxiety disorder (1993-2008) } & Anxiety disorder (1979-1988) & $1.61(0.98-2.66)$ & 0.063 \\
\hline & MDE (1979-1988) & $1.21(0.79-1.86)$ & 0.385 \\
\hline & SUD (1979-1988) & $1.12(0.68-1.83)$ & 0.658 \\
\hline & Female sex & $1.52(1.00-2.31)$ & 0.051 \\
\hline & Aggressiveness (1988) ${ }^{a}$ & $1.17(0.92-1.49)$ & 0.191 \\
\hline & Extraversion $(1988)^{\mathrm{a}}$ & $0.83(0.67-1.04)$ & 0.099 \\
\hline & Neuroticism (1988) ${ }^{a}$ & $1.32(1.01-1.72)$ & $0.040^{*}$ \\
\hline \multirow[t]{7}{*}{ SUD (1993-2008) } & SUD (1979-1988) & $7.07(4.37-11.46)$ & $<0.001^{*}$ \\
\hline & MDE (1979-1988) & $2.17(1.36-3.44)$ & $0.001^{*}$ \\
\hline & Anxiety disorder (1979-1988) & $1.08(0.61-1.89)$ & 0.801 \\
\hline & Female sex & $0.50(0.32-0.77)$ & $0.002^{*}$ \\
\hline & Aggressiveness (1988) ${ }^{\mathrm{a}}$ & $0.90(0.65-1.25)$ & 0.515 \\
\hline & Extraversion $(1988)^{\mathrm{a}}$ & $0.89(0.70-1.14)$ & 0.363 \\
\hline & Neuroticism $(1988)^{\mathrm{a}}$ & $1.12(0.86-1.48)$ & 0.398 \\
\hline \multirow[t]{8}{*}{ Depression treatment use (1993-2008) } & MDE treatment use (1979-1988) & $2.78(1.66-4.65)$ & $<0.001^{*}$ \\
\hline & MDE (1979-1988) & $1.53(0.97-2.42)$ & 0.067 \\
\hline & Anxiety disorder (1979-1988) & $0.84(0.51-1.38)$ & 0.493 \\
\hline & SUD (1979-1988) & $1.43(0.88-2.31)$ & 0.147 \\
\hline & Female sex & $1.43(0.89-2.31)$ & 0.141 \\
\hline & Aggressiveness (1988) ${ }^{a}$ & $0.93(0.71-1.21)$ & 0.577 \\
\hline & Extraversion $(1988)^{\mathrm{a}}$ & $0.96(0.75-1.22)$ & 0.723 \\
\hline & Neuroticism $(1988)^{a}$ & $1.41(1.10-1.82)$ & $0.008^{*}$ \\
\hline
\end{tabular}

OR, Odds ratio; $\mathrm{CI}$, confidence interval; MDE, major depression episode; SUD, substance use disorder.

${ }^{a}$ Continuous variable. ORs for continuous variables refer to a one standard deviation increase on the respective scale.

* Significant predictor $(p<0.05)$.

occurrence of psychopathology yielded no significant effects for both aggressiveness and extraversion. In contrast, neuroticism as assessed in 1988 significantly predicted the subsequent repeated occurrence between 1993 and 2008 of $\mathrm{MDE}(\mathrm{OR}=1.41)$, anxiety disorder $(\mathrm{OR}=1.32)$ and depression treatment use $(\mathrm{OR}=1.41)$. Since neuroticism was assessed as a standardized continuous variable, its OR refers to a one standard deviation (S.D.) increase. That is, with respect to a future major depression, a 1 s.D. increase in neuroticism increased the odds of MDE and depression treatment use by $41 \%$ each, whereas the odds of subsequent anxiety disorder were increased by $32 \%$. Note that the risk increases exponentially with each further increase of 1 S.D. unit: while the OR for a 1 S.D. increase was 1.41 (i.e. $41 \%$ ), it corresponds to 1.96 for a 2 s.D. increase (i.e. $96 \%$ ) and to 2.75 for a 3 s.D. increase (i.e. $175 \%$ ).

To ascertain a strict temporal sequencing where scores on personality domains precede onset of psychopathology, we excluded all participants with a past 10-year history of either MDE, anxiety disorder, depression treatment use and SUD prior to personality assessment and reran the GEE model (see model 2 in Table 3). The cumulative rates of first-onset cases between 1993 and 2008 of MDE, anxiety disorders and SUD were $15.5 \%(n=63), 20.9 \%(n=85)$ and $12.3 \%$ $(n=50)$. The results of model 2 show that neuroticism significantly predicted the first-time incidence of subsequent MDE $(\mathrm{OR}=1.53)$ and depression treatment use $(\mathrm{OR}=1.84)$. Using the formula provided by Zhang \& $\mathrm{Yu}$ (1998) to transform ORs into risk ratios produced a relative risk for first-time MDE of 1.41. As indicated above the unconditional risk for first-time occurrence of MDE between 1993 and 2008 was 15.5\% (cumulative incidence); hence, persons with a neuroticism score of 1 S.D. above the mean had an absolute risk of $21.9 \%$. This represents an absolute risk increase of $6.4 \%$. Being 2 s.D. above the mean in neuroticism increased the risk 
Table 3. Model 2: prospective associations between personality domains and psychopathology in persons without MDE, anxiety disorder and depression treatment use between 1979 and 1988 (204 participants) as well as in persons without SUD between 1979 and 1988 (280 participants)

\begin{tabular}{|c|c|c|c|}
\hline Outcome & Predictors & OR $(95 \% \mathrm{CI})$ & $p$ \\
\hline \multirow[t]{4}{*}{ MDE (1993-2008) } & Female sex & $1.02(0.56-1.86)$ & 0.945 \\
\hline & Aggressiveness (1988) ${ }^{\mathrm{a}}$ & $1.17(0.85-1.60)$ & 0.332 \\
\hline & Extraversion $(1988)^{\mathrm{a}}$ & $1.12(0.83-1.50)$ & 0.475 \\
\hline & Neuroticism $(1988)^{a}$ & $1.53(1.05-2.23)$ & $0.029^{*}$ \\
\hline \multirow[t]{4}{*}{ Anxiety disorder (1993-2008) } & Female sex & $1.04(0.59-1.83)$ & 0.890 \\
\hline & Aggressiveness (1988) ${ }^{\mathrm{a}}$ & $1.24(0.90-1.72)$ & 0.185 \\
\hline & Extraversion $(1988)^{\mathrm{a}}$ & $0.98(0.72-1.34)$ & 0.916 \\
\hline & Neuroticism $(1988)^{a}$ & $1.40(0.91-2.14)$ & 0.128 \\
\hline \multirow[t]{4}{*}{ SUD (1993-2008) } & Female sex & $0.71(0.39-1.29)$ & 0.262 \\
\hline & Aggressiveness (1988) ${ }^{\mathrm{a}}$ & $0.97(0.62-1.52)$ & 0.894 \\
\hline & Extraversion $(1988)^{\mathrm{a}}$ & $0.77(0.58-1.03)$ & 0.079 \\
\hline & Neuroticism $(1988)^{\mathrm{a}}$ & $1.08(0.79-1.49)$ & 0.629 \\
\hline \multirow[t]{4}{*}{ Depression treatment use (1993-2008) } & Female sex & $1.59(0.83-3.06)$ & 0.165 \\
\hline & Aggressiveness $(1988)^{\mathrm{a}}$ & $0.88(0.60-1.28)$ & 0.495 \\
\hline & Extraversion $(1988)^{\mathrm{a}}$ & $1.21(0.81-1.80)$ & 0.348 \\
\hline & Neuroticism $(1988)^{a}$ & $1.84(1.24-2.74)$ & $0.003^{*}$ \\
\hline
\end{tabular}

MDE, Major depression episode; SUD, substance use disorder; OR, odds ratio; CI, confidence interval.

${ }^{a}$ Continuous variable. ORs for continuous variables refer to one standard deviation increase on the respective scale.

* Significant predictor $(p<0.05)$.

for future MDE from $15.5 \%$ to $30.0 \%$, which corresponds to an absolute increase of $14.5 \%$ (relative risk 1.9 ).

We conducted sensitivity analyses using the original FPI scales of extraversion and neuroticism as defined by the authors (Fahrenberg et al. 1984). Those analyses consistently replicated the results indicated above by producing the same significant associations between personality and affective disorders. We additionally reran all analyses by including the stratification weight to adjust the results for the sample stratification. The stratification weight was not significantly related to any outcome when personality traits were included and it did not significantly alter the associations between mental disorders and personality as reported in Tables 2 and 3. Finally, an alternative conceptualization of the umbrella diagnosis of anxiety disorder comprising all DSM-IV anxiety disorders, that is, social phobia, specific phobia, agoraphobia, obsessive-compulsive disorder, panic disorder and GAD was additionally tested. This broad anxiety disorder diagnosis produced the identical significant personality main effects as reported in Tables 2 and 3.

\section{Discussion}

\section{Summary of the evidence}

This longitudinal epidemiological study is unique in various respects. First, to the best of our knowledge, it is the only study to span a total observation period of 30 years in a prospectively followed and repeatedly assessed adult cohort. Second, in contrast to studies that adjusted baseline measurement for concurrent psychopathology only (e.g. Krueger, 1999; De Graaf et al. 2002), in a first step we statistically controlled for the past 10 years of mental disorder prevalence and, in a second step, we restricted our prospective analysis to persons with no history of mental disorders across the past 10 years prior to personality assessment, which provides a more stringent adjustment. Third, instead of predicting the outcome as assessed at one single time point only (e.g. Kendler et al. 2006; Turiano et al. 2012), here we projected the effect of personality traits to repeatedly assessed subsequent measures of psychopathology, again providing a more accurate estimate due to probable fluctuations in symptomatology over time and substantially biased retrospective prevalence estimates (see Moffitt et al. 2010; Takayanagi et al. 2014). We additionally included depression treatment use because it serves as a good proxy for particularly burdensome depression episodes (Hengartner et al. 2016). Since the categorical DSM diagnosis of major depression lacks reliability, validity and clinical utility (Parker, 2005; Lorenzo-Luaces, 2015), consideration of distinctly severe depression episodes independent of DSM diagnostic criteria provides valuable information.

The results show that neuroticism as assessed in 1988 , with a prior 10 -year history of mental disorders 
(i.e. 1979-1988) adjusted for, significantly predicted future MDE, anxiety disorders and depression treatment use as assessed three times between 1993 and 2008. Moreover, when persons with a history of MDE, depression treatment or anxiety disorder between 1979 and 1988 were excluded, neuroticism significantly predicted the first-time incidence of subsequent MDE (OR $=1.53)$ and depression treatment use $(\mathrm{OR}=1.84)$. The strength of associations was substantial and the effect of neuroticism is highly significant from a public health perspective, as expressed by an absolute increase of $6.4 \%$ in the risk of first-time occurrence of MDE over the subsequent 15-year follow-up period for persons with a neuroticism score 1 S.D. above the mean. With respect to persons with a neuroticism score of 2 s.D. above the mean, the absolute risk increase was a remarkable $14.5 \%$. This figure is even more impressive when one considers that the annual prevalence rate for major depression in the general population in Europe and the USA falls well below 10\% (see Alonso et al. 2004; Kessler et al. 2005).

\section{Competing aetiological models}

Conceptually we may delineate three broad aetiological models of the personality-psychopathology association: the pathoplasty model, the shared-factor/ spectrum model and the causal model (Widiger, 2011). Within these broad categories there are more fine-grained distinctions. For instance, some authors differentiate the common-cause model from the spectrum model, while others commonly refer to the predisposition or vulnerability model instead of the causal model (Clark, 2005; Klein et al. 2011). As summarized above, we found compelling evidence for a temporally sequenced relationship between neuroticism and depression that may be suggestive of a causal relationship. That association not only held for psychiatric diagnoses, but also for carefully assessed depression treatment use, which provides compelling convergent validity and support for the notion that persons scoring high on neuroticism use mental health services more frequently (Goodwin et al. 2002; ten Have et al. 2005).

The common-cause and spectrum models posit that mental disorders and personality traits arise from the same causal factor, but are themselves not causally related (Klein et al. 2011). In order to rule out effects of common-cause and spectrum models, aetiological influences (genetic and environmental) should be strictly adjusted for. This is a test that we cannot perform with our data and that is not advised by the literature anyway, since neuroticism and major depression show a considerable genetic overlap (Hettema et al. 2006; Kendler et al. 2006). It is therefore legitimate to conclude that shared (genetic) factors are certainly involved in the development of both neuroticism and major depression (for a review, see Klein et al. 2011). Yet, by adjusting for a history of MDE and anxiety disorder we ensured that variance in personality domains attributable to shared aetiological factors was removed. Moreover, by replicating the prospective effect of neuroticism on the subsequent development of MDE in persons with no immediate history of affective disorders, we established a clear temporal sequencing that is prerequisite for the predisposition model and that cannot be accounted for by the shared factor models. Testing and accounting for the pathoplasty model was not possible, because we had no detailed information on the course of disorder episodes and no data on treatment responses. However, since the pathoplasty model does only account for the trajectory and severity of a disorder, but not for its occurrence (Klein et al. 2011), focusing on the first-time incidence of mental disorders subsequent to personality assessment as applied in model 2 rules out its effects. Finally, we were not able to examine reversed causality, that is, effects of psychopathology on personality, since in the Zurich Cohort Study personality was assessed at one single time point only. However, by examining the association between personality and psychopathology in persons with no history of affective disorders across the past 10 years prior to personality assessment we were also able to rule out the effects of both the scar and complication models on the outcome (see Clark, 2005). By this means we can preclude that high scores in neuroticism were merely caused by preceding affective disorders. Thus, in line with the literature, there is no compelling evidence for both the scar and complication models (Ormel et al. 2004; De Fruyt et al. 2006; Morey et al. 2010).

The exact nature of the personality-depression association is most likely the result of a synergism between different causal effects and best explained by the dynamic interplay of several aetiological models, in particular, $(a)$ the shared-factor models, $(b)$ the predisposition model, and $(c)$ the pathoplasty model (Klein et al. 2011). Specifically, (a) major depression and neuroticism share a substantial proportion of genetic variance (e.g. Kendler et al. 2006), but (b) neuroticism is also causally related to the onset of MDE by increasing the vulnerability for depression following stressful life events (e.g. Kendler et al. 2004). Finally, once an episode of major depression has developed, (c) persons scoring high on neuroticism show a less favourable illness course and poorer treatment response (e.g. Quilty et al. 2008). Thus, although alternative aetiological models may certainly explain some variance in the outcome, on the basis of our stringent statistical modelling we suggest that neuroticism is in part an independent 
risk factor that predisposes persons to severe and impairing depression episodes. Further evidence of a causal link between neuroticism and internalizing disorders would also provide a unique opportunity for effective and sustainable prevention and intervention programmes in these disorders (Lahey, 2009; Barlow et al. 2014).

Conflicting with some findings (e.g. Krueger, 1999), but in accordance with others (e.g. De Graaf et al. 2002), neuroticism did not independently predict subsequent SUD in our prospective prediction model, because in our data the effect of past SUD markedly outweighed the effects of personality (see Table 2). However, that does not necessarily imply that the predisposition model does not apply to SUD. It could be that the specific temporal sequencing in the Zurich Cohort Study made it impossible to detect an independent effect of personality. Probably, personality traits assessed around age 20 years, that is, before the vast majority of people had started to abuse substances (see Angst et al. 2016), would have produced different results. An alternative interpretation would be that neuroticism correlates with SUD, but does not independently predict SUD (for a comprehensive meta-analysis, see Kotov et al. 2010). This would suggest that the relationship between neuroticism and SUD corresponds to the pathoplasty or the common-cause/spectrum models, but not to the causal predisposition model. Finally, extraversion failed to independently predict MDE or anxiety disorders in our test of the predisposition model. This finding converges with the literature insofar as various studies have shown that the prognostic validity of extraversion is either weak or fails to independently predict psychopathology in prospective studies (Krueger, 1999; Kendler et al. 2006; Fanous et al. 2007). Nevertheless, it should be kept in mind that in interrelation with neuroticism, introversion may influence the severity of depression (Clark, 2005; Kotov et al. 2010).

\section{Limitations}

The following limitations need to be considered when interpreting these findings: first, all data relied on selfreport. Although psychiatric information was carefully evaluated and gauged through repeated comprehensive semi-structured interviews, we cannot exclude a certain bias due to either the effects of social desirability or reduced self-awareness. In a related vein, since all data relied on the same source, shared method variance might have inflated the reported associations. However, as suggested by an anonymous reviewer, self-reported personality dimensions appear to outperform clinical diagnoses of personality disorders with respect to their predictive validity (Morey et al. 2012), which is why self-report personality inventories may not necessarily constitute a limitation. Second, all analyses were based on cumulative information over the 12 months prior to the interviews (i.e. 12-month prevalence rates of mental disorders). This restriction was necessary in order to collect reliable data that was not biased through recall, since retrospective assessments of lifetime prevalence have been shown to yield markedly underestimated rates (Moffitt et al. 2010; Takayanagi et al. 2014). Nevertheless, persons may have suffered from mental disorders during the time gaps that were not covered by the annual prevalence rates from one of the seven measurement occasions, which would result in an underestimation of the true effect size. Moreover, since the first assessment of mental disorders was at age 20/21 years, we do not know whether some participants may have experienced serious mental health problems during adolescence that were not captured through reoccurrences during adulthood. But again, since prospectively followed cohort studies (e.g. Moffitt et al. 2010; Angst et al. 2016) yield considerably higher lifetime prevalence rates than retrospectively assessed lifetime prevalence rates that should, theoretically, also cover adolescence (e.g. Alonso et al. 2004; Kessler \& Wang, 2008) we suggest that serious mental health problems were mostly captured in the present study (for a direct comparison of prospective $v$. retrospective assessment, see Takayanagi et al. 2014). Third, personality domains were assessed only once in 1988 when participants were aged 29/30 years. This made it possible for us to adjust effects of personality for the 10-year prevalence of mental disorder prior to 1988, which is a substantial advantage of the present study. On the other hand, the drawback of this onetime assessment was that personality was measured at a point in life when the incidence of many mental disorders had already occurred (Angst et al. 2016). As a consequence, a large proportion of psychopathology that could have been attributable to personality if the latter had been assessed for instance at age 19/20 years was partialled out through the adjustment for preceding mental disorders. This has certainly reduced the strength of prospective personality associations, which is why the present analysis provides a conservative test of the predisposition model rather than a liberal one. This is also a plausible explanation as to why personality domains failed to prospectively predict SUD. Nevertheless, we do not regard this conservative estimation as a weakness of our study, but rather as a strength, since it increases the validity of the reported associations. Fourth, there is some phenomenological overlap between personality and psychopathology. For instance, many personality traits include psychopathological symptoms, which may spuriously increase the association between personality and psychopathology 
(Klein et al. 2011). However, since we rigorously adjusted our prediction models for past psychopathology, we contend that this potential bias was adequately addressed in the present study.

\section{Conclusions}

Consistent with recent reviews (Lahey, 2009; Klein et al. 2011; Hengartner, 2015), the present study demonstrates that maladaptive personality, and in particular excessively high neuroticism, is substantially related to poor mental health and functioning. In particular, our data corroborate the notion that neuroticism is an independent risk factor that predisposes to future depression episodes and treatment thereof, even when past mental disorders are rigorously accounted for. This has serious and far-reaching clinical implications that by now have also started to be emphasized in various psychiatric specialities. In fields such as psychopharmacology (Tang et al. 2009), genetics (Genetics of Personality Consortium et al. 2015), health economics (Cuijpers et al. 2010), nosology (Griffith et al. 2010) and psychotherapy (Barlow et al. 2014), new trends in research have suggested that it might prove beneficial in the long term to focus on neuroticism instead of its various secondary clinical consequences that comprise the disorders of the internalizing spectrum. Neuroticism is also the predominant trait underlying personality disorders (Samuel \& Widiger, 2008; Hengartner et al. 2014a). These are highly debilitating disorders that pervasively increase the persistence of common mental disorders, including depression (Skodol et al. 2011), anxiety disorders (Skodol et al. 2014) and SUD (Hasin et al. 2011), as well as social functioning deficits (Hengartner et al. 2014c) and low quality of life (Cramer et al. 2006). Most importantly, the conceptual revision of the personality disorders for International Classification of Diseases, 11th revision (ICD-11) proposes that personality dysfunction may be diagnosed as early as in childhood and adolescence (see Tyrer et al. 2015), which would allow researchers to put the assumption that maladaptive personality predates severe and persistent psychopathology to the test (Tyrer, 2015). In concert with many others (e.g. Clark, 2005; Krueger \& Eaton, 2010; Barlow et al. 2014; Skodol et al. 2014; Tyrer et al. 2015) we therefore suggest that dimensional ratings of (maladaptive) personality traits play an important role in psychopathology and should be addressed in both psychiatric research and clinical practice.

\section{Acknowledgements}

This work was supported by the Swiss National Science Foundation (grant number 32-50881.97).

\section{Declaration of Interest}

None.

\section{References}

Alonso J, Angermeyer MC, Bernert S, Bruffaerts R, Brugha TS, Bryson H, de Girolamo G, Graaf R, Demyttenaere K, Gasquet I, Haro JM, Katz SJ, Kessler RC, Kovess V, Lépine JP, Ormel J, Polidori G, Russo LJ, Vilagut G, Almansa J, Arbabzadeh-Bouchez S, Autonell J, Bernal M, Buist-Bouwman MA, Codony M, Domingo-Salvany A, Ferrer M, Joo SS, Martínez-Alonso M, Matschinger $H$, Mazzi F, Morgan Z, Morosini P, Palacín C, Romera B, Taub N, Vollebergh WA; ESEMeD/MHEDEA 2000 Investigators, European Study of the Epidemiology of Mental Disorders (ESEMeD) Project (2004). Prevalence of mental disorders in Europe: results from the European Study of the Epidemiology of Mental Disorders (ESEMeD) project. Acta Psychiatrica Scandinavica 109, 21-27.

Angst J, Clayton P (1986). Premorbid personality of depressive, bipolar, and schizophrenic patients with special reference to suicidal issues. Comprehensive Psychiatry 27, 511-532.

Angst J, Dobler-Mikola A, Binder J (1984). The Zurich Study - a prospective epidemiological study of depressive, neurotic and psychosomatic syndromes. I. Problem, methodology. European Archives of Psychiatry and Neurological Sciences 234, 13-20.

Angst J, Gamma A, Neuenschwander M, Ajdacic-Gross V, Eich D, Rössler W, Merikangas KR (2005). Prevalence of mental disorders in the Zurich Cohort Study: a twenty year prospective study. Epidemiologia e Psichiatria Sociale 14, 68-76.

Angst J, Paksarian D, Cui L, Merikangas KR, Hengartner MP, Ajdacic-Gross V, Rössler W (2016). The epidemiology of common mental disorders from age 20 to 50: results from the prospective Zurich cohort Study. Epidemiology and Psychiatric Sciences 25, 24-32.

Barlow DH, Sauer-Zavala S, Carl JR, Bullis JR, Ellard KK (2014). The nature, diagnosis, and treatment of neuroticism: back to the future. Clinical Psychological Science 2, 344-365.

Bogg T, Roberts BW (2013). The case for conscientiousness: evidence and implications for a personality trait marker of health and longevity. Annals of Behavioral Medicine 45, 278-288.

Caspi A, Houts RM, Belsky DW, Goldman-Mellor SJ, Harrington H, Israel S, Meier MH, Ramrakha S, Shalev I, Poulton R, Moffitt TE (2014). The p factor: one general psychopathology factor in the structure of psychiatric disorders? Clinical Psychological Science 2, 119-137.

Clark LA (2005). Temperament as a unifying basis for personality and psychopathology. Journal of Abnormal Psychology 114, 505-521.

Connor-Smith JK, Flachsbart C (2007). Relations between personality and coping: a meta-analysis. Journal of Personality and Social Psychology 93, 1080-1107.

Cramer V, Torgersen S, Kringlen E (2006). Personality disorders and quality of life. A population study. Comprehensive Psychiatry 47, 178-184. 
Cuijpers P, Smit F, Penninx BW, de Graaf R, ten Have M, Beekman AT (2010). Economic costs of neuroticism: a population-based study. Archives of General Psychiatry 67, 1086-1093.

De Fruyt F, Van Leeuwen K, Bagby RM, Rolland JP, Rouillon F (2006). Assessing and interpreting personality change and continuity in patients treated for major depression. Psychological Assessment 18, 71-80.

De Graaf R, Bijl RV, Ravelli A, Smit F, Vollebergh WA (2002). Predictors of first incidence of DSM-III-R psychiatric disorders in the general population: findings from the Netherlands Mental Health Survey and Incidence Study. Acta Psychiatrica Scandinavica 106, 303-313.

Depla MF, ten Have ML, van Balkom AJ, de Graaf R (2008). Specific fears and phobias in the general population: results from the Netherlands Mental Health Survey and Incidence Study (NEMESIS). Social Psychiatry and Psychiatric Epidemiology 43, 200-208.

Derogatis LR (1977). Symptom Checklist 90, R-Version Manual I: Scoring, Administration, and Procedures for the SCL-90. Johns Hopkins Press: Baltimore, MD.

Dunn G, Pickles A, Tansella M, Vazquez-Barquero JL (1999). Two-phase epidemiological surveys in psychiatric research. British Journal of Psychiatry 174, 95-100.

Eich D, Ajdacic-Gross V, Condrau M, Huber H, Gamma A, Angst J, Rössler W (2003). The Zurich Study: participation patterns and Symptom Checklist 90-R scores in six interviews, 1979-99. Acta Psychiatrica Scandinavica Supplement 108, 11-14.

Eysenck SBG, Eysenck HJ (1975). Manual of the EPQ (Eysenck Personality Questionnaire). Educational and Industrial Testing Service: San Diego, CA.

Fahrenberg J, Hampel R, Selg H (1984). Das Freiburger Persönlichkeitsinventar FPI. Revidierte Fassung FPI-R und teilweise geänderte Fassung FPI-A1, 4. revidierte Auflage. Hogrefe: Göttingen.

Fahrenberg J, Hampel R, Selg H (2001). Das Freiburger Persönlichkeitsinventar FPI. Handanweisung, 7. überarbeitete und neunormierte Auflage. Hogrefe: Göttingen.

Fanous AH, Neale MC, Aggen SH, Kendler KS (2007). A longitudinal study of personality and major depression in a population-based sample of male twins. Psychological Medicine 37, 1163-1172.

Genetics of Personality Consortium, de Moor MH, van den Berg SM, Verweij KJ, Krueger RF, Luciano M, Arias Vasquez A, Matteson LK, Derringer J, Esko T, Amin N, Gordon SD, Hansell NK, Hart AB, Seppälä I, Huffman JE, Konte B, Lahti J, Lee M, Miller M, Nutile T, Tanaka T, Teumer A, Viktorin A, Wedenoja J, Abecasis GR, Adkins DE, Agrawal A, Allik J, Appel K, Bigdeli TB, Busonero F, Campbell H, Costa PT, Davey Smith G, Davies G, de Wit H, Ding J, Engelhardt BE, Eriksson JG, Fedko IO, Ferrucci L, Franke B, Giegling I, Grucza R, Hartmann AM, Heath AC, Heinonen K, Henders AK, Homuth G, Hottenga JJ, Iacono WG, Janzing J, Jokela M, Karlsson R, Kemp JP, Kirkpatrick MG, Latvala A, Lehtimäki T, Liewald DC, Madden PA, Magri C, Magnusson PK, Marten J, Maschio A, Medland SE, Mihailov E, Milaneschi Y, Montgomery GW, Nauck M, Ouwens KG, Palotie A, Pettersson E,
Polasek O, Qian Y, Pulkki-Råback L, Raitakari OT, Realo A, Rose RJ, Ruggiero D, Schmidt CO, Slutske WS, Sorice R, Starr JM, St Pourcain B, Sutin AR, Timpson NJ, Trochet H, Vermeulen S, Vuoksimaa E, Widen E, Wouda J, Wright MJ, Zgaga L, Porteous D, Minelli A, Palmer AA, Rujescu D, Ciullo M, Hayward C, Rudan I, Metspalu A, Kaprio J, Deary IJ, Räikkönen K, Wilson JF, KeltikangasJärvinen L, Bierut LJ, Hettema JM, Grabe HJ, van Duijn CM, Evans DM, Schlessinger D, Pedersen NL, Terracciano A, McGue M, Penninx BW, Martin NG, Boomsma DI (2015). Meta-analysis of genome-wide association studies for neuroticism, and the polygenic association with major depressive disorder. JAMA Psychiatry 72, 642-650.

Goodwin RD, Hoven CW, Lyons JS, Stein MB (2002). Mental health service utilization in the United States. The role of personality factors. Social Psychiatry and Psychiatric Epidemiology 37, 561-566.

Griffith JW, Zinbarg RE, Craske MG, Mineka S, Rose RD, Waters AM, Sutton JM (2010). Neuroticism as a common dimension in the internalizing disorders. Psychological Medicine 40, 1125-1136.

Harris JM, Cherkas LF, Kato BS, Heiman JR, Spector TD (2008). Normal variations in personality are associated with coital orgasmic infrequency in heterosexual women: a population-based study. Journal of Sexual Medicine 5, 1177-1183.

Hasin DS, Fenton MC, Skodol AE, Krueger RF, Keyes KM, Geier T, Greenstein E, Blanco C, Grant BF (2011). Personality disorders and the 3-year course of alcohol, drug, and nicotine use disorders. Archives of General Psychiatry 68, 1158-1167.

Hengartner MP (2015). The detrimental impact of maladaptive personality on public mental health: a challenge for psychiatric practice. Frontiers in Psychiatry 6, 87.

Hengartner MP, Ajdacic-Gross V, Rodgers S, Müller M, Rössler W (2014a). The joint structure of normal and pathological personality: further evidence for a dimensional model. Comprehensive Psychiatry 55, 667-674.

Hengartner MP, Angst F, Ajdacic-Gross V, Rössler W, Angst J (2016). Treated versus non-treated subjects with depression from a 30-year cohort study: prevalence and clinical covariates. European Archives of Psychiatry and Clinical Neuroscience 266, 173-180.

Hengartner MP, De Fruyt F, Rodgers S, Müller M, Rössler W, Ajdacic-Gross V (2014b). An integrative examination of general personality dysfunction in a large community sample. Personality and Mental Health 8, 276-289.

Hengartner MP, Müller M, Rodgers S, Rössler W, AjdacicGross V (2014c). Interpersonal functioning deficits in association with DSM-IV personality disorder dimensions. Social Psychiatry and Psychiatric Epidemiology 49, 317-325.

Hettema JM, Neale MC, Myers JM, Prescott CA, Kendler KS (2006). A population-based twin study of the relationship between neuroticism and internalizing disorders. American Journal of Psychiatry 163, 857-864.

Kendler KS, Gatz M, Gardner CO, Pedersen NL (2006). Personality and major depression: a Swedish longitudinal, 
population-based twin study. Archives of General Psychiatry 63, 1113-1120.

Kendler KS, Kuhn J, Prescott CA (2004). The interrelationship of neuroticism, sex, and stressful life events in the prediction of episodes of major depression. American Journal of Psychiatry 161, 631-636.

Kessler RC, Chiu WT, Demler O, Merikangas KR, Walters EE (2005). Prevalence, severity, and comorbidity of 12month DSM-IV disorders in the National Comorbidity Survey Replication. Archives of General Psychiatry 62, 617-627.

Kessler RC, Wang PS (2008). The descriptive epidemiology of commonly occurring mental disorders in the United States. Annual Review of Public Health 29, 115-129.

Khan AA, Jacobson KC, Gardner CO, Prescott CA, Kendler KS (2005). Personality and comorbidity of common psychiatric disorders. British Journal of Psychiatry 186, 190-196.

Klein DN, Kotov R, Bufferd SJ (2011). Personality and depression: explanatory models and review of the evidence. Annual Review of Clinical Psychology 7, 269-295.

Kotov R, Gamez W, Schmidt F, Watson D (2010). Linking "big" personality traits to anxiety, depressive, and substance use disorders: a meta-analysis. Psychological Bulletin 136, 768-821.

Krueger RF (1999). Personality traits in late adolescence predict mental disorders in early adulthood: a prospective-epidemiological study. Journal of Personality 67, 39-65.

Krueger RF, Eaton NR (2010). Personality traits and the classification of mental disorders: toward a more complete integration in DSM-5 and an empirical model of psychopathology. Personality Disorders 1, 97-118.

Lahey BB (2009). Public health significance of neuroticism. American Psychologist 64, 241-256.

Leeners B, Hengartner MP, Rössler W, Ajdacic-Gross V, Angst J (2014). The role of psychopathological and personality covariates in orgasmic difficulties: a prospective longitudinal evaluation in a cohort of women from age 30 to 50. Journal of Sexual Medicine 11, 2928-2937.

Lorenzo-Luaces L (2015). Heterogeneity in the prognosis of major depression: from the common cold to a highly debilitating and recurrent illness. Epidemiology and Psychiatric Sciences 24, 466-472.

Macare C, Bates TC, Heath AC, Martin NG, Ettinger U (2012). Substantial genetic overlap between schizotypy and neuroticism: a twin study. Behavior Genetics 42, 732-742.

Markon KE, Krueger RF, Watson D (2005). Delineating the structure of normal and abnormal personality: an integrative hierarchical approach. Journal of Personality and Social Psychology 88, 139-157.

Moffitt TE, Caspi A, Taylor A, Kokaua J, Milne BJ, Polanczyk G, Poulton R (2010). How common are common mental disorders? Evidence that lifetime prevalence rates are doubled by prospective versus retrospective ascertainment. Psychological Medicine 40, 899-909.

Morey LC, Hopwood CJ, Markowitz JC, Gunderson JG, Grilo CM, McGlashan TH, Shea MT, Yen S, Sanislow CA, Ansell EB, Skodol AE (2012). Comparison of alternative models for personality disorders, II: 6-, 8- and 10-year follow-up. Psychological Medicine 42, 1705-1713.

Morey LC, Shea MT, Markowitz JC, Stout RL, Hopwood CJ, Gunderson JG, Grilo CM, McGlashan TH, Yen S, Sanislow CA, Skodol AE (2010). State effects of major depression on the assessment of personality and personality disorder. American Journal of Psychiatry 167, 528-535.

Ormel J, Oldehinkel AJ, Vollebergh W (2004). Vulnerability before, during, and after a major depressive episode: a 3-wave population-based study. Archives of General Psychiatry 61, 990-996.

Parker G (2005). Beyond major depression. Psychological Medicine 35, 467-474.

Pearlin LI, Schooler C (1978). The structure of coping. Journal of Health and Social Behavior 19, 2-21.

Quilty LC, De Fruyt F, Rolland JP, Kennedy SH, Rouillon PF, Bagby RM (2008). Dimensional personality traits and treatment outcome in patients with major depressive disorder. Journal of Affective Disorders 108, 241-250.

Rössler W, Ajdacic-Gross V, Müller M, Rodgers S, Haker H, Hengartner MP (2015). Assessing sub-clinical psychosis phenotypes in the general population - a multidimensional approach. Schizophrenia Research 161, 194-201.

Samuel DB, Widiger TA (2008). A meta-analytic review of the relationships between the five-factor model and DSM-IV-TR personality disorders: a facet level analysis. Clinical Psychology Review 28, 1326-1342.

Skodol AE, Geier T, Grant BF, Hasin DS (2014). Personality disorders and the persistence of anxiety disorders in a nationally representative sample. Depression and Anxiety 31, 721-728.

Skodol AE, Grilo CM, Keyes KM, Geier T, Grant BF, Hasin DS (2011). Relationship of personality disorders to the course of major depressive disorder in a nationally representative sample. American Journal of Psychiatry 168, 257-264.

Soskin DP, Carl JR, Alpert J, Fava M (2012). Antidepressant effects on emotional temperament: toward a biobehavioral research paradigm for major depressive disorder. CNS Neuroscience and Therapeutics 18, 441-451.

Spek V, Nyklicek I, Cuijpers P, Pop V (2008). Predictors of outcome of group and Internet-based cognitive behavior therapy. Journal of Affective Disorders 105, 137-145.

Tackett JL, Lahey BB, van Hulle C, Waldman I, Krueger RF, Rathouz PJ (2013). Common genetic influences on negative emotionality and a general psychopathology factor in childhood and adolescence. Journal of Abnormal Psychology 122, 1142-1153.

Takayanagi Y, Spira AP, Roth KB, Gallo JJ, Eaton WW, Mojtabai R (2014). Accuracy of reports of lifetime mental and physical disorders: results from the Baltimore Epidemiological Catchment Area study. JAMA Psychiatry 71, 273-280.

Tang TZ, DeRubeis RJ, Hollon SD, Amsterdam J, Shelton R, Schalet B (2009). Personality change during depression treatment: a placebo-controlled trial. Archives of General Psychiatry 66, 1322-1330. 
ten Have M, Oldehinkel A, Vollebergh W, Ormel J (2005). Does neuroticism explain variations in care service use for mental health problems in the general population? Results from the Netherlands Mental Health Survey and Incidence Study (NEMESIS). Social Psychiatry and Psychiatric Epidemiology 40, 425-431.

Turiano NA, Whiteman SD, Hampson SE, Roberts BW, Mroczek DK (2012). Personality and substance use in midlife: conscientiousness as a moderator and the effects of trait change. Journal of Research in Personality 46, 295-305.

Tyrer P (2015). Personality dysfunction is the cause of recurrent non-cognitive mental disorder: a testable hypothesis. Personality and Mental Health 9, 1-7.
Tyrer P, Reed GM, Crawford MJ (2015). Classification, assessment, prevalence, and effect of personality disorder. Lancet 385, 717-726.

Van Os J, Jones PB (2001). Neuroticism as a risk factor for schizophrenia. Psychological Medicine 31, 1129-1134.

Widiger TA (2011). Personality and psychopathology. World Psychiatry 10, 103-106.

Zeger SL, Liang KY, Albert PS (1988). Models for longitudinal data: a generalized estimating equation approach. Biometrics 44, 1049-1060.

Zhang J, Yu KF (1998). What's the relative risk? A method of correcting the odds ratio in cohort studies of common outcomes. JAMA 280, 1690-1691. 